\title{
How do teachers perceive meaningful leadership? Overview of a qualitative exploration
}

\author{
Ahmet Göçen \\ Harran University, Faculty of Education, Turkey
}

\begin{abstract}
Leaders' self-realization and their intra-group behaviors at work are influenced by elements such as a sense of meaningful purpose and intrinsic motivation. This study aims to construct a model of meaningful leadership, based on the values, aspirations, and attitudes of a leader and how these qualities help them develop positive organizational cultures. The research, based on constructivist grounded theory design, utilized semi-structured interview technique with 15 teachers, examining their perceptions of meaningfulness and leadership. These interviews revealed ten core dimensions of meaningful leadership: An ultimate purpose in life, sharing meaning, understanding, linking the past, present, and future, wisdom, peacefulness, a sense of ethics, serving others, inner motivation, and fostering unity. These dimensions can be considered essential when identifying meaningful leaders. This proposed model of leadership, with a focus on meaningfulness, can play a pivotal role in an organization by contributing to self-realization of members and ensuring the unity of purpose. In educational organizations, a meaningful leadership approach can leverage leaders' efforts by providing an intrinsic motivation source for all school members.
\end{abstract}

Keywords: Meaningful leadership; Meaning-based leadership; Meaningfulness; Teachers

Article History: Submitted 18 October 2020; Revised 3 January 2021; Published online 19 January 2021

\section{Introduction}

In the last decades, organizational leadership literature has begun to consider meaningfulness and spirituality as important aspects of management (Klenke, 2005; Yang, Huang, \& Wu, 2019). Terms like spirituality, meaning and meaningfulness were previously outside the purview of behavioral scientists, who focused on observable behavior or patterns (Kriger \& Seng, 2005). Though the terms "meaning" and "meaningfulness" have long been considered in religious and psychology studies; spiritual leadership (Fairholm, 1996; Fry, 2003) and workplace spirituality (Ashmos \& Duchon, 2000) have examined meaning and meaningful work as research topics in contemporary organizational leadership journals. In addition, meaning-centered leadership studies that focus on the meaning-making role of leaders have gradually made their way into the leadership literature (Jackson, 2017, Herrera, 2017). More recently, an understanding of leadership based on

\footnotetext{
Address of Corresponding Author

Ahmet Göçen, PhD, Harran University, Faculty of Education, 63190, Haliliye, Şanlıurfa, Turkey.

$\triangle$ agocen@harran.edu.tr

0000-0002-9376-2084
}

How to cite: Göçen, A. (2021). How do teachers perceive meaningful leadership? Overview of a qualitative exploration. Journal of Pedagogical Research, 5(1), 31-49. http:/ / dx.doi.org/10.33902/JPR.2021066866 
meaningfulness and meaning has appeared in respected academic journals (Frémeaux \& Pavageau, 2020; Van Knippenberg, 2020). This interest obliges researchers to consider meaningfulness within an organizational leadership lens and bring new perspectives into leadership and meaningfulness at work. Herrera (2017, p.46) clearly states the reason why one needs to embark on a such study "With the evolution of organizations and the influx of changes over the last century, especially in regard to technology and social structures, many individuals seek a leader willing to fulfill their needs as they, in most cases, subconsciously climb the hierarchy of needs pyramid".

This study proposes to add a new model of leadership through the lens of meaningfulness based in educational management ecosystem. To clarify this proposed leadership model, a review of literature has been conducted. The concepts of meaningfulness, leaders as drivers of meaning and intrinsic motivation are explored and from these, a model of meaningful leadership is proposed.

\subsection{Literature Review}

The term of meaningful leadership has occurred in several articles, journals and books in the last decade (See, DeMara, 2018; Thornton, 2018). However, it is within the study of Frémeaux and Pavageau (2020) that the term was examined in detail. Based on 42 interviews with leaders, including 27 life story interviews, the authors examined the extent to which leaders give meaning to leadership practices; practices that are regarded by current literature as factors contributing to meaningful work. Another recent paper, written by Van Knippenberg (2020), states meaningbased leaders' role to build a shared sense of purpose within their organization. It is no wonder todays' leaders are expected to maintain an irrefutable role of enabling and framing "meaning" in the organization (Mautz, 2015, p.197) and the 21st century community expects meaning-making role of leaders within a contemporary and practical leadership model (Herrera, 2017).

The literature of leadership explored the concepts of "ethics, spirituality, servanthood, toxicity, vision, charisma" from which new leadership models have been built. Each leadership concept seems to have clarified one aspect of general leadership. The societal changes of the 21st century with their focus on acquisition and material life have caused people to search for a greater "meaning" in their life. The turbulent and uncertain world seems to affect people at a deeper level, leading them to actively look for more meaning in their lives (Holbeche \& Springett, 2004). Current leadership trends at work, driven by technological advancement and the need for constant innovation, require work environments that foster meaning (Jackson, 2017, p.v). Today, more and more people value meaningful work over high paying employment. For some, work has become more than merely a way to earn an income (Frémeaux \& Pavageau, 2020). Varney (2009) states people desire meaningful work or a job that is intrinsically satisfying. Effective leadership must involve meaning-making. Thus, new leadership models must consider how leaders can embed meaning-making into the core of their organization. However, there is little information about the process through which leadership and individual orientations are brought together to promote work meaningfulness (Matsuo, Arai, \& Matsuo, 2019). The meaningful leadership model proposed in this study could help organizations see how meaningful leadership is manifested and what qualities are to be nurtured.

\subsubsection{Meaningfulness}

Meaningfulness has been defined as "the quality of being useful, serious, or important (a), the quality of showing or having meaning (b)" and meaning is "what something expresses or represents" (Cambridge Dictionary, n.d.). In organizational work literature, "meaningfulness of work" is defined as "employees' beliefs that their work has at least one distinct purpose that they also consider to be personally significant" (Robertson, O’Reilly, \& Hannah, 2020, p.598).

Korotkov (1998) defines meaningfulness as what makes people's life emotionally sensible. By this definition, meaningfulness fosters a feeling of energy and commitment to meet whatever demands are confronted in life. Thus, teachers sacrifice their time and energy, as long as they 
consider their purpose in life and work as worthwhile. For this study, meaningfulness is defined as people's deep understanding of their existential purpose and their feeling of inner satisfaction when pursuing professional purpose. In this respect, meaningfulness is fostered through one's understanding of purpose. Actions towards that meaningful purpose lead to intrinsic motivation and self-satisfaction; that is, a fit between what is believed and what is done.

If we consider work as a search for meaning, then today's organizations - from schools to the service sector - are expected to provide suitable conditions for this search. To achieve more happiness in their job, employees need to know how their work contributes to the organization's overall performance. When we can see where our work fits into the whole picture, our work can be seen as meaningful (Kerns, 2013) and beneficial to other people. Modern organizations often put several degrees of separation between producers and users, leading to a reduced level of meaning at work (Chalofsky \& Krishna, 2009). However, teachers are still good examples of this original view of meaningfulness, as their contribution to students can be seen as a contribution to society and the world. One role of school leaders is to establish a link among teachers between what is believed and done, creating a sense of meaningful purpose, contributing to sustained growth of their organization. Ulrich and Ulrich (2010) suggest that leaders bridge strategy and execution, promoting sustainable growth by helping employees find meaning at work.

\subsubsection{Leaders as drivers of meaning}

Most of existing meaningful leadership studies are written in regard to meaningfulness at work. Lips-Wiersma and Morris (2009, p. 491) states much of the managerial research on meaningful work has focused on examining ways to manage "meaning" through leadership or organizational culture. Thus, there is a nexus connecting meaningful work, leadership studies and the meaningmaking role of leaders.

Leaders are meaning-makers, since one of their critical roles is to establish meaning and purpose in their organization (Ulrich \& Ulrich, 2010). In fact, 21st century communities expect their leaders to be meaning makers (Herrera, 2017). By clarifying and fostering meaning in their organization, leaders can help all employees give meaning to their work (Frémeaux \& Pavageau, 2020). Accordingly, Van Knippenberg (2020) suggests that a leader's clearer understanding of organizational purpose will motivate members - through meaning - and can contribute to the pursuit of the organizational purpose. The different perspectives and new studies on leadership can, then, be viewed as signaling a change toward the leader's role to a manager of meaning and as a visionary (Parry \& Bryman, 2006).

Leaders with a strong sense of meaning, guide not only their life journey, but also their followers, in finding their own meaning in work and in life. DeMara (2018) states people do not stay in an organization where they do not have meaning. These leaders distinguish their leadership skills by their clarity of purpose, their passion, and their courage to explore and act on possibilities (Graham, 2011). They help their followers by creating an environment for them to find meaning at work. Finding that meaning, in turn, will bring their followers' whole selves - mind, body, emotion, and spirit - to their work (Chalofsky \& Krishna, 2009). This wholeness may help protect employees, such as teachers, from burnout or emotional problems.

Teachers' contracts can be limited to specific tasks, which may not fully describe the range of activities needed to fully promote effective learning within the classroom. However, leaders who express themselves and signify their purpose may build loyalty among teachers and form the collective efficacy necessary for making meaningful changes to their workplace (Sosik, 2000). Thus, leaders as meaning-makers, and those who align their followers' meaning with that of their organization, can inspire beyond the limits of contracts and transform organizational goals into the personal goals for each member of that organization.

\subsubsection{Meaningfulness and intrinsic motivation}

Studies suggest meaningfulness at work is generally associated with increased levels of motivation and engagement at work (Mostafa \& Abed El-Motalib, 2020). Motivation can be fostered through 
several sources: physical needs, goals, beliefs, meaning and meaningfulness. There are clear conceptual links between an understanding of an organization's purpose, meaning and motivation at work (Van Knippenberg, 2020). Leaders with goals and strong meaning ascribed to them can make difference, and they can leverage the efforts towards the organizational goals by spreading this spirit in the organization. Thus, Carton (2018) states the assumption that leaders can increase the motivation of employees by spreading the organization's ultimate aspirations and goals in the group. Creating meaningfulness in a group or sharing the meaning with others can foster motivation and desire to follow organizational purpose.

Based on the theories of Maslow, Herzberg McClelland, and Alderfer, Chalofsky (2003, p. 71) asserts that people are motivated to take actions based on fulfilling their needs. As people meet their basic needs and move forward, they are more attuned to intrinsic motivation and not only begin to act on meaningfulness, but also meaning they ascribe to their goals. This explains why Chalofsky and Krishna (2009) consider meaningfulness as a deeper level of intrinsic motivation. Maslow similarly (1969a) specified the later modification of the original model, adding a new level, called "self-transcendence," beyond above self-actualization. Self-transcendence is deeply correlated with one's ultimate goals and meanings ascribed to these goals. Thus, a meaningful leader can be said to be driven by their deepest motivational factors, revealed in selftranscendence. Fully developed human beings - meaningful leaders, in my view - can be said to be motivated by values that transcend themselves (Maslow, 1969b).

\subsection{Purpose of the Study}

In the last decades, the concept of meaning within leadership has been generally studied within spiritual leadership, spirituality in the workplace studies (e.g., Ashmos \& Duchon 2000; Fry, 2003, Kinjerski \& Skrypnek, 2004; Milliman, Czaplewski, \& Ferguson, 2003). Meaningful leadership is an emerging area of general research in leadership theory. This is currently explored under the terms of "meaning-based, meaning-centered or meaningful leadership". Research in leadership within these terms has been explored by Frémeaux and Pavageau (2020), Van Knippenberg (2020), Bartels and Jackson (2021). Research has yet to reach a uniform understanding of meaningful leadership. This study, while it is in line with the growing literature on meaning/fulness in organizational studies, aims to build a meaningful leadership model based on teachers' perspectives.

\section{Method}

This study is in the form of grounded theory within qualitative research methodology. Grounded theory is defined as a systematic, yet flexible methodology to collect and analyze qualitative data for building theories or models (Charmaz, 2006). Hunter, Murphy, Grealish, Casey, and Keady (2011) define three types of grounded theory designs based on the related literature: Classic, Straussian and Constructivist. Similarly, Chun-Tie, Birks and Francis (2019) mentions traditional, evolved and constructivist grounded theory designs. In this study, a constructivist grounded theory approach was adopted as this design holds the researcher as a co-producer of the data, due to the interaction between researcher and the participant that produces the data (Charmaz, 1996). Data collection process may not be separated from the researcher, in contrast to classical grounded theory design (Charmaz, 2006). Meanings in the process were reflected and discussed with participants to form a model on meaning/meaningfulness at work, by which leaders can manage their organizations effectively. A comparative analysis was generated to uncover dimensions and characteristics within meaningful leadership.

\subsection{Participants}

Data from a group of teachers was collected to help meaningful leadership literature expand in terms of educational organizations. The study was conducted with 15 teachers, each interview conducted at various times during the 2019-2020 academic year. Table 1 lists the group of teachers, working at a variety of schools from primary to high schools. Before interviewing these teachers, 
data was collected from a focus group and online data from teachers as well as school managers in the region. All participants in the study were from schools in southeast Turkey.

Theoretical sampling was used to select the teachers for interviews. Birks and Mills (2015, p.10) states "to sample theoretically, the researcher makes a strategic decision about what or who will provide the most information-rich source of data to meet their analytical needs." Theoretical sampling helps a researcher select the sampling in line with the research questions and intended measurements and plans. Participant invitation was based on their involvement in teacher trainings or master's degree program from a University in Turkey. The rationale for this was the proven interest in their personal development as teachers. Recruitment was also based on questions. For example, in initial interviews, detailed discussions were held with school counselors and religious studies teachers to explore meaningfulness from religious and psychology perspectives. Following this, teachers from other areas were interviewed, to determine their understanding of meaningfulness and leadership. Teachers from master's degree programs in education management were also invited to participate to provide further insight into meaningful leadership based on theories and knowledge gained through their coursework. Other participants were recruited to compare or consolidate meaningful leadership dimensions present in previous interview transcripts. The purpose was to compare findings from teachers and control the trustworthiness of the study. In keeping with grounded study methodology, extended online interviews were conducted with some participants post initial interview to further clarify emergent topics.

All data collection was completed in person, by mail/online tools and by phone (especially for second/third interviews coinciding with Covid-19 school closures). Ethics permission was obtained from Harran University's Social and Human Sciences Ethics Committee. Consent was obtained from each volunteer prior to interviews. Expected durations of interviews were explained, as well as the participants' rights to withdraw at any time. Pseudonyms were used to maintain the participants' confidentiality and anonymity in interviews. Table 1 presents the participants' information: gender, school branch and type.

Table 1

Characteristics of the participants

\begin{tabular}{lllllc}
\hline & Pseud. & Gender & Branch & School Type & Year \\
\hline \multirow{6}{*}{ Dilan } & Female & Science Teacher & Sci-Art Center & 8 \\
& Fatih & Male & School Counsellor & Middle School & 6 \\
& Halil & Male & School Counsellor & Middle School & 7 \\
& Yasin & Male & Nursery Teacher & Primary School & 7 \\
& Tarik & Male & Turkish Language Teacher & Middle School & 34 \\
Teacher & Neslihan & Female & Religious Studies Teacher & High School & 4 \\
Group & Nergis & Female & English Language Teacher & Middle School & 5 \\
& Ali & Male & School Counsellor & High School & 8 \\
& Kerime & Female & English Language Teacher & High School & 9 \\
& Nalan & Female & Class Teacher & Primary School & 3 \\
& Osman & Male & School Counsellor & Middle School & 3 \\
& Meral & Female & Class Teacher & Primary School & 13 \\
& Mustafa & Male & Special Education Teacher & Primary School & 10 \\
& Leyla & Female & Computer Science Teacher & Middle School & 5 \\
& Hasan & Male & Religious Studies Teacher & Middle School & 4 \\
\hline
\end{tabular}

\subsection{Data Collection}

Before actual and detailed teacher interviews, answers from pilot group discussion and online data from teachers and school managers were examined. The pilot groups' answers were helpful in 
eliciting more information for the actual interviews. The pilot group consisted of 4 deputy school managers, 5 school managers and 9 teachers who were registered to non-thesis program in a university in southeast of Turkey. Based on those first screenings, the groups were seen to share many positive ideas on meaningful leaders from "beneficial to dedicated". The most recurring qualities were related to "benefit to all, purpose, wisdom, ideals, tolerance, setting example". These qualities were the guiding dimensions for actual teachers' interviews, which were also highlighted by them as well. Crosschecking pilot groups' short answers with actual detailed teacher interviews provided the triangulation of data sources (Salkind, 2010).

The participants were asked the following questions: "What does meaningfulness (meaning in life) mean? How would you define a leader that acts on meaningfulness? What are the characteristics that could differentiate a meaningful leader from others?" The participants were also asked to tell about their experiences of meaningful leadership that they observed in their school or other organizations. All these questions were the main ones supported with contextbased questions throughout the conversations. Through constant comparative analysis as suggested by Strauss and Corbin (1998), the questions were adapted to explore emergent issues as well. Each interview prompted additional questions. For example, in one interview, Fatih said "meaning is not universal or assumed the same by all". Subsequent participants were asked "Do you think if there is universally assumed meaning/s or does each person has their very subjective meaning?" Second/third interviews were conducted when required, with the same participants. In-person interviews lasted between 30 - 60 minutes. The second interviews included follow-up questions to understand perceptions of meaningful leadership more clearly, to broaden opinions and compare them with other participants' ideas. A third round of interviews and online discussions were conducted with participants having more academic backgrounds (e.g. Halil).

\subsection{Data Analysis and Interpretation}

Initially, the focus (pilot) group's comments in group discussion and the comments through online forms were examined. Following this, 15 teachers were given in-depth interviews, constantly comparing topics. Since the pilot group discussion and online data were in short format and conducted to determine main orientations for this leadership type, direct quotations for this group were not included in the findings section. In-depth interviews were longer, and sometimes involved second or third interview with the same participant to determine more clearly their understanding of meaningful leadership. Thematic saturation occurred by analysis of the 15th interview, at which no further participants were recruited. Pilot study's general findings concurred with this decision.

Analyst triangulation was applied to data analysis, as explained by Patton (1999), by incorporating another analyst in the process. The other analyst from educational leadership field contributed to verification and validation of qualitative analysis in the study. All notes, texts and ideas on participant statements were shared. Then, some participants were contacted again for more clarification or asked extended questions for a more in-depth analysis by phone/online tools.

Data coding and analysis were conducted in three steps for detailed teacher interviews, as in constructivist grounded theory. In the initial coding stage, provisional concepts are developed word-by-word or line-by-line. Second, focused coding is based on the categories established by checking and integrating the categories that emerge from the initial coding. Last, theoretical coding was used to unearth the core category and integrate the theoretical framework (Lee, Clarke, Carson, \& Yang, 2018). Patton (2014) shows that a grounded theory pattern study proceeds from open to selective; or from low- to high-level concepts. Thus, a detailed examination of codes was executed from open to selective concepts. Data analysis began right after the first interview, which facilitated simultaneous collection, coding, and analysis of the data (Giles, De Lacey, \& MuirCochrane, 2016). A short example of initial codes and subsequent codes generated from the analysis are included in Table 2. 
Table 2

A short example of initial codes and subsequent codes

\begin{tabular}{|c|c|c|}
\hline Interview Excerpt (From Nalan) & $\begin{array}{l}\text { Initial Codes } \\
\text { Immediately After the } \\
\text { First Interview }\end{array}$ & Focused Code \\
\hline $\begin{array}{l}\text { Leaders can infuse meaning into } \\
\text { their work and also transfer this } \\
\text { trait into other people to make } \\
\text { them happy. }\end{array}$ & $\begin{array}{l}\text { Infusing meaning into work } \\
\text { Transferring meaning to others }\end{array}$ & $\begin{array}{l}\text { Spreading } \\
\text { meaning at work }\end{array}$ \\
\hline
\end{tabular}

Initial codes and focused codes in Table 2, supported by other participants' ideas, formed the "sharing meaning" dimension under meaningful leadership in this study. As the interviews progressed, constant comparisons of processes between interview participants produced themes. Similarly, Giles et al. (2016) first defined initial codes immediately after the first interview and then initial codes after recoding the interviews. This led to focused codes and categories based on theoretical sensitivity and reflexivity. To render credibility, direct quotations, interpretations, and conclusions are shared with the participants; to solicit their ideas and consent. In the final form, the direct quotes/manuscript were checked by a native speaker in English to check whether translated quotes make sense and were understandable for international readers. The quotations are rendered in indentations.

\subsection{Research Trustworthiness}

Guba and Lincoln (1982) mention four criteria for trustworthiness in qualitative studies: credibility, dependability, confirmability, and transferability. All possible validity and reliability issues were tackled by following selective strategies, such as participant confirmation, to delineate the limits of the research, show distorted points, quote participant views in detail, etc. Triangulation, ensuring honesty in informants, thick descriptions, member checks for credibility, descriptions of the study context, the method and participants for transferability, the operational detail of data gathering, outlining the research design for dependability, giving limitations, and triangulation by another expert for confirmability were followed as suggested by Shenton (2004). All findings, themes and raw data were presented to another analyst for cross-checking, and possible missing/non-matching points. The second analyst had a background of educational leadership and experience in qualitative data analysis. The analyst read all transcripts and texts, along with codes and themes for which suggestions and possible directions were given.

Despite the efforts to foster trustworthiness in research, this study has some limitations as Covid-19 pandemic coincided with the data collection period. The interviews were at some time conducted thorough other medias such as phones, mails. In some cases, online face-to-face interaction tools were used to get participants' ideas after first interviews. This may have created a negative effect in collection of data as face-to-face interviews make it easier to understand feelings of participants.

\section{Findings}

This study was carried out to formulate a model of meaningful leadership. The findings are grouped in three parts below.

\subsection{Meaning and Meaningfulness}

Meaningfulness - sometimes stated as " a sense of meaning" by participants in Turkish contextcan be defined as understanding the purpose of life and the level of joy felt in journey toward a person's ultimate goals. Thus, it depends on a spiritual bond between persons and their acts. Participants in the study generally linked "meaning" to "pure goals" and also to the "questioning 
of the self," "a person's embodiment of their beliefs," "the essence of creation" and "the pursuit of the truth". Participants used meaningfulness and meaning interchangeably in some cases, though they have differences. Table 3 shows the ideas of participants on definition of meaning and meaningfulness.

Table 3

Meaning and meaningfulness based on participants' ideas

\begin{tabular}{ll}
\hline Meaningfulness & Meaning \\
\hline - The level of joy felt in journey toward a person's & - Pure goals \\
ultimate goals & - Questioning of the self \\
- Understanding the life purpose & - A person's embodiment of their beliefs \\
- The creation of a spiritual bond between persons & - The essence of creation \\
and their act & \\
- One's living according to his or her values, life & - The pursuit of the truth \\
goals, and beliefs &
\end{tabular}

Neslihan defined her idea of meaningfulness as "one's living according to his or her values, life goals, and beliefs". Another participant Yasin stated that, "Meaning is the essence of creation and meaningful life is a long-term action that harbors purpose, effort, and self-satisfaction".

Although participants' definition of meaning is somehow linked to "purpose," the meaning of "meaning" seemed to change from person to person since they perceive the world differently. Similarly, Nalan used Frankl's (2006) idea of meaning, stating, "Meaning changes from person to person, from day to day and hour to hour." Similarly, Ali said: "Just like the facts, the meaning can be changed, developed, rearranged". Fatih presented a holistic perspective:

The meaningful life is living a filtered life, which means that one believes in one goal, filtering many other things and lesser ideals. These filters are shaped by religion and past experiences, so we cannot tell of a universal meaning, but rather different meanings for each person.

All of these show meaning can change. People are actually in search of their meaning of life as the facts people know for now may be subject to change over time.

\subsection{Conceptualizing Meaningful Leadership}

Participant explanations caused a problem in defining meaningful leaders. Consider one school principal whose goal it was to earn respect in her field. She spent day and night focusing on her school's national examination results. For another principal, earning respect might include a laser focus on the wellbeing of her students and fostering their desire to study. Which one is meaningful leadership? They both seem to share an ultimate goal, in their perspective, and exert much effort toward meeting that goal. Both of their actions and thoughts are completely in line with some of studies' participants regarding their concepts of meaningfulness.

During second conversations with Fatih, Neslihan, and Tarık about the concept of meaningful leadership on spiritual, transcendent, and positive values, they suggested that meaningful leadership could be examined under two forms: "positive meaning-making and negative meaningmaking." As Fatih put it, "World leaders that swept countries into "despair" and "glory" with a view to universal values can be given as examples under these forms". Fatih meant there could be leaders with self-sacrifice, huge effort, care for others and his nation, but they may base this understanding as a supreme superiority of their group over others, which is not humanistic. 
Figure 1

The dimensions of Meaningful Leadership based on participants' opinions

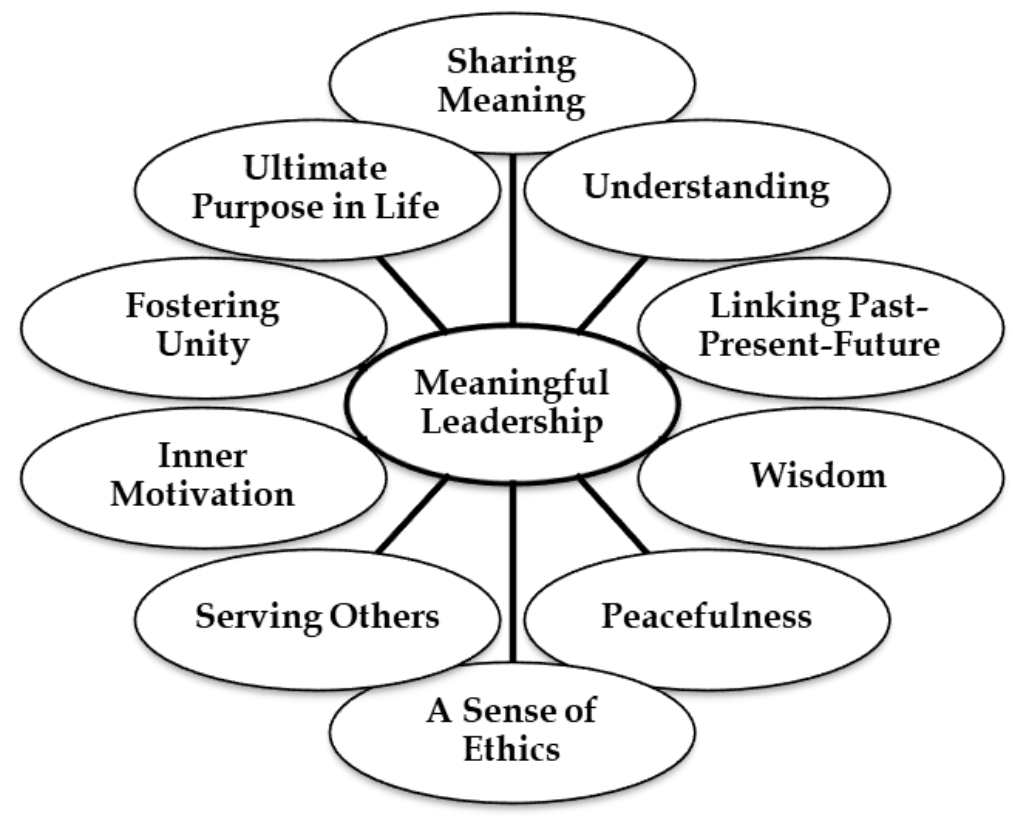

Figure 1 gives visualization to dimensions within meaningful leadership. Each of these qualities are explained separately below with "quotes" from the participants.

\subsubsection{An ultimate purpose in life}

Meaningful leaders have spiritual and meaningful goals in their life that tie their inner world to the outside world. They also exert a great deal of effort in attaining goals that are tailored to their continuous self-growth and that of others, contributing to society, helping people in need, and setting an example for humanity. Halil defined meaningful leaders according to these goals. He asserted, "A meaningful leader is the person who sacrifices himself for the sake of his goals, guided by reason." Similar to that, Hasan defined a meaningful life as "Achieving a goal, target, or principle in life and making efforts to achieve it can be defined as a meaningful life."

Meaningful leaders try to find a link between their work and their values or principles to infuse passion into what they do. Osman stated:

Individuals look for reasons (at work) that they think these can contribute to their life purpose. If they think that they cannot find these and that the work does not contribute to their life goals and it does not make sense, they will probably quit their work or no contribution can be obtained from them.

When the ideas of participants are analyzed at holistic level, teachers need a meaningful goal, and it needs to comply with their values and life goals. When organizational and personal goals become incompatible, people may lose their passion and pride in their work.

\subsubsection{Sharing meaning}

Meaningful leaders are focused on sharing their meaningfulness or desire to understand the meaning of the life with others. They always want others to enjoy self-growth and realization by searching for their own meaning or adopting a purpose to further the wellbeing of humanity. They support others in their own quest for meaning. Nalan gave an example of a person she sees as a meaningful leader, counting the traits of coherence and fairness, among others, to be essential in a meaningful leader. She expressed, "Leaders can infuse meaning into their work and also transfer this trait into other people to make them happy." Meral added to what Kerime said, stating "A meaningful leader must share all his meaning with the organization and the people around him. Kerime asserted that: 
A meaningful leader provides the necessary environment for the colleagues. He encourages those who have acquired their inner motivation, protecting their emotion [meaningful path], as well as providing an encouraging atmosphere for those who lack meaning in life or are on the road toward finding their own meaning.

Leaders in classical terms may share the organizational goals with the members of their group; however, the important thing is to foster a meaning creation in the organization that attracts all members. It is a process by which the value of self-growth for each member is expressed and they are supported to find their own cause for work without materialistic concern.

\subsubsection{Understanding}

Meaningful leaders are understanding, and they desire to be understood. Understanding here covers -- but extends beyond -- empathy and sympathy. It means grasping the essence of event and persons; they need to understand the people around them and always have room for them. Meaningful leaders give importance to the people around them, even if they share divergent opinions. Leyla said "They are constructive, dedicated and are very understanding." Meral had similar ideas, stating that "Meaningful leaders must focus on understanding their followers in every aspect... and they listen to all of them." Tarık explained his views on this aspect of meaningful leaders as, "School leaders will look into the eyes of their teachers, infuse them with peace, and provide support from their heart... these leaders understand their colleagues and also give a chance for others to understand them."

Meaningful leaders in an organization listen to people and are attentive to their needs. If they are criticized for what they did, they listen or accept it in peace with wisdom. If they make a mistake, they see it as a natural part of human life.

\subsubsection{Linking past, present and, future}

The participants defined meaningful leadership as the ability to connect the past, present, and future into a coherent whole. They explained that they take lessons from the past, focus on the now with an "in-the-moment" orientation, and work for the future with a vision. Mustafa explained how he and his colleagues handle this integration as "Where we come from, why we come, what we need to do, and where we' re going are all certain [in meaningful leaders]." Tar1k explained that meaningful leaders focus on "knowing the past, looking forward to the future." Dilan defined one of the qualities of a meaningful leader as "s/he is the one that makes the most of now." Nalan summarized her idea, "Meaningful leaders, I think, they act forward-looking; they work by thinking ahead, focusing on how their current work will reveal the situation that will make him happy in the future."

All related statements by the participants indicate that meaningful leaders think of their past (be it negative or positive), focus on the present, and - at the same time - become visionaries, as they think of their purpose to reach their goals and act to realize those goals. Linking past, present and, future is an also important in decision making for meaningful leaders as they try to understand the essence of the events and have decisions with wisdom and more self-awareness.

\subsubsection{Wisdom}

Meaningful leaders are deeply involved in self-growth and learning. They have a lifetime commitment to learning and self-development. They all believe it is better to grow in wisdom than wealth. Nergis pointed out that the desire for wisdom and learning is a distinct feature of a meaningful leader. She said:

Meaningful leadership is the most comprehensive and broad type of leadership, and it has a deeper aspect that contains wisdom. It is a type of leadership that directs society, sets an example, aims for peace and love, and fascinates people with its knowledge.

Neslihan also pointed out that a meaningful leader hones his or her wisdom and peacemaking skills "They have a wise or contemplative aspect; they also have a sense of peace that can calm people down."

The participants' observations all imply that meaningful leaders are self-growth-oriented people, striving for wisdom, and fostering peace and harmony throughout the organizations. 


\subsubsection{Peacefulness}

Meaningful leaders have high levels of self-awareness and self-contentedness, both of which help them to be at peace with themselves. Furthermore, they are at peace with others and try to create peace in their lives as well. Mustafa explained that, "A person who finds his own meaning in life -being a part of that meaning -- gives him peace of mind and helps him to get rid of the troublesome situations in which he lives." Neslihan added that, "If there are happiness and peace in an organization in line with its goals, this characteristic might show that the leader exhibits meaningful behaviors, and meaningful leaders have aspects which make people relieved and at peace." Another participant, Tark asserted that, "Meaningful leaders are at peace, communicating with, and accepting [their employees' unique personhood]."

Based on participants' ideas, peace can be manifested in various ways; it can be a latent, but focused action to change the things around people. It can be in the form of "favor of silence" for keeping all the things as they are so as not to cause disturbance. Peacefulness in this model highlights the authentic contentedness one has with his life and people around them and accepting them as they are.

\subsubsection{A sense of ethics}

The participants' perceptions of meaningful leadership included many qualities ascribed to the ethicality and morality desired in these leaders. These qualities are explained under one dimension here, which includes setting an example, fairness, being coherent (walk the talk), fighting for the right things despite challenges. Mustafa explained this perspective, "Despite crises and chaotic situations that might occur within the organization, a meaningful leader should ensure justice within the organization using the framework of ethical principles." The participants provided examples of Prophet Abraham, Jesus, Muhammed and figures like Gandhi, Dalai Lama from different beliefs, engineers like Leonarda da Vinci, country founders and leaders like Atatürk as well as writers like Frankl, as examples of meaningful leaders who act with ethics, endurance and coherency in the path toward achieving their goals. Meral stated that, "These persons make no concessions when hardships arise and become warriors to overcome these hardships." Kerime clarified meaningful leadership in terms of taking a coherent stand amid hardships:

Meaningful leaders have patience against hardship and are strictly bound by their "meaning," a quality which makes them ambitious and coherent... [referencing a quote from Nietzsche] 'He who has a why to live can bear almost any how.

Meaningful leaders are principled- meaning that they do not approve anything that is not ethical. Participants mainly implied that meaningful leaders, without any excuse, follow what is right, even if it means pain and hardships for them. These are the ethical standards expected from meaningful leaders.

\subsubsection{Serving others}

Most of the participants believed that one of the core characteristics of a meaningful leader is the help such a leader provides for society - their non-pragmatic support to people in need. They help with no expectation of anything in return. Nalan said that, "If there is meaning, there is a benefit...If $a$ person gives meaning to his work, he sustains not only himself but also all the other individuals." Hasan added, "Living the meaningful life is to make a living that is beneficial for both other people and themselves and to put their effort...toward this end." Meral stated that, "[In meaningful organizations], employees are aware of their contribution to society and work with this end in mind.". Another participant, Tarik asserted that "meaningful leaders are for disadvantaged people" implying that these leaders always support persons in need. Within the dimension of serving others, the participants highlighted humbleness as the most visible manifestation of servanthood. Serving or service to others is generally associated with servant leadership. The participants think meaningful leaders are there to help people and benefit their team mates as the higher goals towards self-transcendence necessitate them to think not only their own self but also others' needs. 


\subsubsection{Inner motivation}

Most of the participants stated that meaningful leaders are inner motivated and this leadership has a firm connection with a person's inner world. After all, it is a person's inner side that inspires them to commit to their goals. The participants pointed out that they need an effective source of motivation to keep them on track to achieve their goals. As Meral put it, "Meaning-based leadership is based solely on inner motivation, and it is similar to spiritual leadership in that they are both fed from inner sources." Leyla explained, "It is inner motivation that gives meaning rather than a materialistic concern." Osman stated that people find an inner power to keep them in pursuit of their goals, saying:

Life is a long marathon filled with difficult turns for many of us. During this marathon, some of us may find the power to overcome the challenges and fatigue from their inner world. In my opinion, these people are those [with inner motivation] who find their lives meaningful.

Leadership is based on leaders' power to motivate others. Meaningful leaders are intrinsically motivated to lead their group based on their meaningful work aspirations and they have inner power to keep them focused. They help others to listen their own voice, which motivates them in their work as well.

\subsubsection{Fostering unity}

Meaningful leaders create a feeling of belonging within a group. As Tarık put it: "A meaningful leader gives [members of a group] the feeling of unity." Meral asserted that, "A meaningful leader establishes the environment needed to foster a feeling of membership". Hasan supported the unity dimension, saying: "A meaningful leader should create a positive corporate culture; employees should feel that they belong to the organization, thanks to their leaders." Osman listed providing harmony and a sense of belonging as one of the key characteristics of meaningful leadership as, "Meaning-oriented leaders have critical skills that they can teach to other members of the organization, one of which is the ability to convey a feeling of belongingness to other members of the working group."

Participants mainly believed unity among colleagues is the result of meaningful work perceptions at work. If people in the same organization have similar meaning of their work, shared mission and vision, they know they all build their own future together and they are contributing to each other.

\section{Discussion}

\subsection{Meaning and Meaningfulness}

Meaning, meaningfulness and a sense of purpose are generally used interchangeably by the participants. Meaning is generally understood as a manifestation of ultimate purpose, existential beliefs, existence or the "why" behind things that happen. Thus, meaning can be said to be subjective for people based on their life and beliefs. Similarly, Frankl (2006) argues that meaning for a person is subjective and can change every moment. Leaders can't form groups having the same world of meaning, but may collect them around a common meaning and purpose.

As Varney (2009) states, leadership is as the ability to create a "meaning field" within a common purpose which empowers people to find their own role and make sense of their lot. People's meaning or sense of meaningfulness play role in their perceptions of effective leadership. A leader can display a good action, but the motivation and meaning ascribed to this act may differ greatly (Phipps, 2010). Thus, it is important to create a shared meaning in the organization.

\subsection{Meaningful Leadership}

This study has attempted to introduce a model of meaningful leadership from the perspective of educators. In this paper, meaningful leadership- based on the results of the study-is defined as "an approach adopted by leaders that nurtures heightened awareness of life goals among others in the organization, which in turn strengthens and satisfies their own sense of meaningfulness". This 
approach aims at focusing on heightened awareness of life and work goals for all organization members along with strengthening their sense of meaningfulness. A broader definition of meaningful leadership, based on this model proposed, includes "an embodiment of leaders' thoughts and acts in their work and social life, based on their ultimate purpose in life, desire to share meaning, willingness to understand others, pursuit of wisdom, tendency to link their past, present and future, inner motivational sources, aspiration for peace in the self and the organization along with attention to ethics, serving others and fostering unity." This embodiment of thoughts and acts will not only support spiritual development in leaders, but also in the whole organization. The proposed meaningful leadership based on participants' opinions is composed of ultimate purpose in life, sharing meaning, understanding, linking the past, present and future, wisdom, peacefulness, a sense of ethics, serving others, inner motivation, and fostering unity.

According to the participants, meaningful leaders are firm believers in an ultimate purpose and follow it with passion. The core dimension of meaningful leadership is related to this purpose. For this reason, a leader may not be solely focused on organizations' short-term goals. This paper considers the ultimate purpose as related to self-actualization and self-transcendence through work. Similarly, Chalofsky (2003) matches the higher-order needs with values, working toward a higher cause, meaningfulness, and a purpose in life. Van Knippenberg (2020) claims that all organizations, profit or nonprofit, realize a purpose other than economic performance in part or in whole.

Sharing meaning signifies the spread of an organization's meaning-making process by the leader. Meaningful leaders foster meaning throughout the organization. They may do this either by sharing their meaning with others or by helping others search for their own meaning. Leaders igniting meaning or helping others search for meaning is highlighted by Thornton (2018) and by Göçen and Terzi (2019) under the "meaning leadership at work", a dimension of their meaningful work scale.

Thornton (2018) defines meaningful leadership as "supporting others in their quest for meaning," - a basic human need - and great leaders help followers find it. This search for meaning is not the imposition of the leaders' personal beliefs. Rather, it fosters in others a personal quest to find their true selves rather than prioritising material concerns in life. Leaders guide meaningmaking processes so that meaning-rich employees create a synergy that leads to the desired results (Ulrich \& Ulrich, 2010). Leaders have an understanding of the people around them. They listen, have empathy, accept mistakes, and make room for all while being attentive to other people's problems. Personal attributes such as listening, fairness, attention, affection and empathy should be evident in them. Meaningful leaders show consideration for personal problems, helping those who are in the greatest difficulty (Frémeaux \& Pavageau, 2020).

Meaningful leaders are the link between the demarcations of time. They take lessons from their past, perform in the present but focus on the future. For this reason, all decisions and actions come from the heart. They aim for the future and their ultimate goals, from both an organizational and a life perspective. Similarly, meaningfulness involves integrating the past, present, and future (Baumeister et al., 2013).

Meaningful leaders pursue wisdom, spiritual knowledge and self-growth. Some of the participants believed that meaningful leaders are continuous learners and represent wisdom in their organizations. Similarly, Batubara (2018, p.74), based on Frankl's conceptualization of meaningfulness, stated, "The meaningfulness of life is often also called the value or wisdom of life," which means that meaningfulness naturally leads a person to attain self-growth.

In his theory of spiritual leadership, Fry $(2003$, p.710) concludes the goals sought by spiritual leadership to "help create a state of mind of inner peace for the benefit of the leaders, their followers, and other stakeholders." Fry's conclusion resonates with this study's findings. Overall, this study's participants described meaningful leaders as having peace and fostering it in others. Starting a search for great answers for humankind can lead to peace (Gårdheim, 2016). 
As the study's participants show, one dimension of meaningful leadership concerns ethical behaviors. These leaders are fair, defenders of what's right, consistent, make no concessions and set an example. As Frémeaux and Pavageau (2020) stated in their meaningful leadership dimensions, such leaders have moral exemplarity, ensuring the consistency between values they promote and practices they adopt. They're consistent - and they "walk the talk". Similarly, Morin (2008, p.22) talks about moral correctness defining it as morally justifiable work, both in its accomplishment and through the results it produces.

Meaningful leaders are a significant benefit to society, with little or no self-interest in their acts towards people. They provide benefit to their friends, organization, and their community. For Lips-Wiersma and Wright (2012) serving others is related to meaningfulness, derived from contributing to the wellbeing of others and the community. Meaningfulness is being a giver to others rather than a taker from others (Baumeister et al., 2013). These characteristics all signify the key components of a meaningful leader.

Meaningful leaders, on the other hand, are fueled by inner motivation which is actually constructed with the world of meaning they have. Meaningfulness is a profound intrinsic motivational factor. Van Knippenberg (2020) cites studies on purpose and meaning as a driver of motivation. He adds that understanding the purpose of one's organization does not only inform, but also motivates people. Fry (2003) also cites inner motivation in his theory of spiritual leadership as one of the main components of spiritual leadership.

As a final remark, meaningful leaders infuse an organization's members with the desire to create a common purpose and mutual understanding. For Thory (2016), unity and harmony with others refer to meaningfulness derived from working together with others. This manifests connection and companionship. Fostering unity refers to a sense of shared values, unity in diversity, and a sense of belonging (Lips-Wiersma \& Wright, 2012). Frémeaux and Pavageau (2020, p.10) list "community spirit" as a dimension of meaningful leadership, by which leaders build a community where "members can contribute to a common cause and develop a sense of belonging."

All these dimensions summarized above within meaningful leadership can be listed in short with their characteristics under Table 4.

Table 4

Dimensions of Meaningful Leadership model

\begin{tabular}{|c|c|}
\hline Dimensions & Characteristics \\
\hline Ultimate Purpose in Life & They believe in a higher purpose and follow it with a passion. \\
\hline Sharing Meaning & $\begin{array}{l}\text { They share their meaning with others or help others find their own } \\
\text { meaning. }\end{array}$ \\
\hline Understanding & $\begin{array}{l}\text { They have a profound understanding of people around them; they } \\
\text { listen, talk, share, and always accommodate others. }\end{array}$ \\
\hline Linking Past-Present-Future & $\begin{array}{l}\text { They take lessons from their past, set goals for the future, and use } \\
\text { their present acts to lead towards the future they envision. }\end{array}$ \\
\hline Wisdom & $\begin{array}{l}\text { They are in constant pursuit of wisdom, spiritual knowledge, and } \\
\text { self-growth. }\end{array}$ \\
\hline Peacefulness & They foster a mindful peace in themselves and among others. \\
\hline A sense of ethics & $\begin{array}{l}\text { They are fair, staunch defenders of what is right, consistent in their } \\
\text { acts, do not concede their beliefs and set an example for the } \\
\text { community. }\end{array}$ \\
\hline Serving Others & $\begin{array}{l}\text { They serve their colleagues, organization, community and } \\
\text { humanity with an attention to others' needs. }\end{array}$ \\
\hline Inner Motivation & $\begin{array}{l}\text { They have a strong inner motivation that helps them in their } \\
\text { journey. }\end{array}$ \\
\hline Fostering unity & $\begin{array}{l}\text { They understand others' needs, differing thoughts and beliefs, yet } \\
\text { creating unity throughout the organization's membership. }\end{array}$ \\
\hline
\end{tabular}




\section{Conclusion}

This study proposes a meaningful leadership model, in line with 21st century calls for inner and spiritual development within the organization. This model is based on ten dimensions: ultimate purpose in life, sharing meaning, understanding, linking the past, present and future, wisdom, peacefulness, a sense of ethics, serving others, inner motivation, and fostering unity. Similar studies (e.g. Jackson, 2017, Hodge, 2017) on meaning and leadership indicated that the leadership traits of character, vision, relationships, wisdom, and inspiration help followers gain meaning and purpose from their work. While the term is new to organizational leadership literature, common dimensions will emerge more clearly as research continues.

This study suggests a model of meaningfulness and leadership so that organizations can identify what constitutes meaningful leadership and define a meaningful leader. There are two important results of the study: the meaningful leadership model and a definition of meaningful leadership. Meaningful leadership can be defined as "an approach adopted by leaders that nurtures heightened awareness of life goals among others in the organization, which in turn strengthens and satisfies their own sense of meaningfulness". This approach aims at creating or supporting shared meaning, satisfying a sense of meaningfulness in leaders and colleagues.

Meaningful leaders are inner motivated, believe in their purpose with a passion, share their passion and feeling of meaningfulness with others according to the proposed model. They understand their employees, consider their past, present and future in decision-making, display virtues of wisdom, foster unity in the group, serve others, have peace within themselves and others along with a sense of ethics. These qualities overlap to some extent with Fremeaux and Pavageau's (2020, p.7-10) meaningful leadership model which includes six new dimensions of meaning that leaders give to leadership activity: "moral exemplarity," "self-awareness," "personal and professional support", "community spirit," "shared work commitment," and "positive attitude toward others and events." When the overlapping dimensions are analyzed, meaningful leaders are exemplary role models (setting examples within ethics), have self-awareness (in relation to wisdom, linking the past, present and future), have community spirit (unity), share work commitment (in line with sharing meaning with others), they provide professional/personal support and are positive toward others and events (serving others with positive approach and understanding). The proposed model extends beyond this to include ultimate purpose in life, inner motivation and peacefulness.

The characteristics and dimensions found in this meaningful leadership study can be linked to other leadership models, including but not limited to, spiritual, ethical, wise, peace, purposedriven, visionary and servant leadership styles. Meaningful leadership includes some qualities of spiritual, ethical, servant and other leadership styles. However, this model differs from them with the stress on meaningfulness and how meaning-making fosters the motivation process inside the person. It also describes why and how leaders can foster and sustain this feeling in their group. The Figure 2 illustrates how different leadership dimensions contribute to meaningful leadership.

Figure 2

Different leadership styles' contributions to Meaningful Leadership

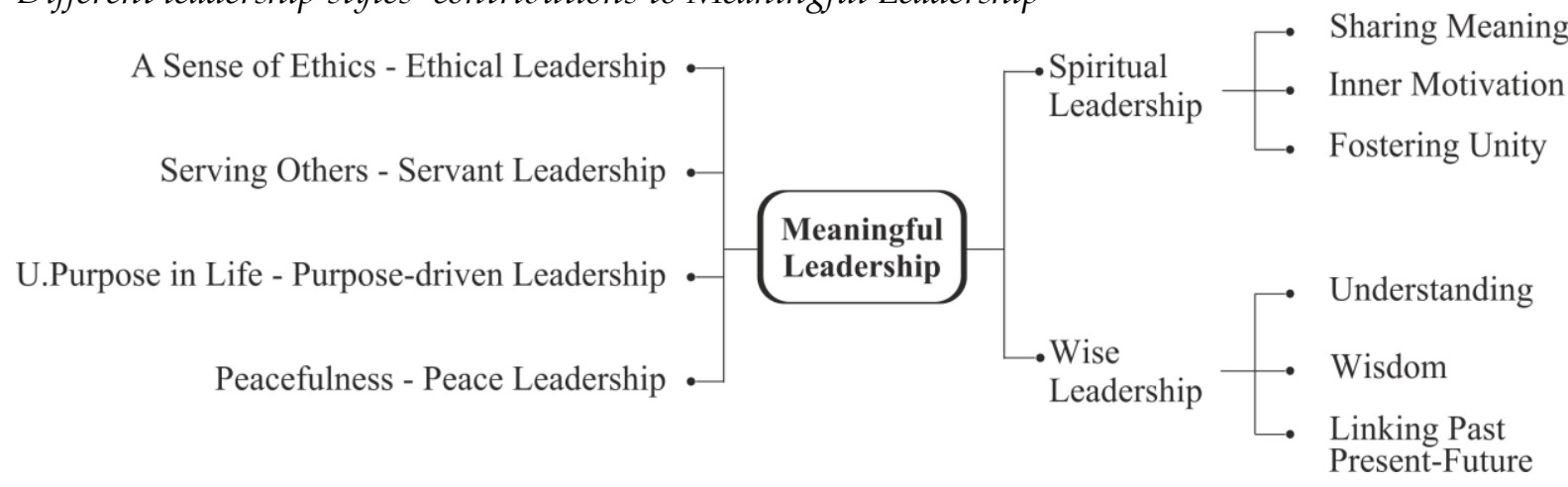


While leadership types may be distinct from each other in their focus, they may still share similar sub-dimensions and qualities. Barbuto and Wheeler (2006) specify "wisdom" among five dimensions of servant leadership, which is the core idea of wise leadership (Nonaka \& Takeuchi, 2011). Spiritual leadership is based on intrinsic motivation (Zou et al, 2020), but the concept of motivation is inherent in many definitions of leading, leadership and leadership styles (Buble, Juras, \& Matić, 2014). Thus, it is natural to see components of other leadership types appearing in other leadership models. A metaphor for this is producing different flavors and tastes from similar ingredients. Among leadership studies, spiritual leadership can be placed in the same broad understanding as meaningful leadership (Fairholm, 1996). Both leadership types strongly address the increasing calls for valuing inner voice of employees at work.

When leadership styles are examined in detail: ethical, servant, purpose-driven, peace, spiritual and wise; they support the notion of meaningful leadership. Meaningful leaders serve their colleagues and community like servant leaders (Greenleaf, 2008); they grasp/understand the essence of the events and persons around them like wise leaders (Nonaka \& Takeuchi, 2011). They desire to create or share meaning with others in the way moral spiritual leaders do (Fairholm, 1996). They act fairly, have coherency and advocate the principled response despite challenges like ethical leaders (Kalshoven, Den Hartog, \& De Hoogh, 2011). They have an ultimate purpose and act with the collective consciousness as purpose-driven leaders (Dantley, 2003) and visionary leaders (Knippenberg, 2020).

Meaningful leaders display these qualities naturally, driven by their world of meaning, based on a higher purpose, self-transcendence or fulfilling themselves as a human. While meaningful leadership is built on the shared dimensions of other leadership styles, it is different as it focuses on "meaning" and "calling". Meaningful leaders help others listen to their higher calling and accept meaningfulness as a gate to the wisdom, ethics, servanthood, unity and peace in themselves and their work. Thus, this meaningful leadership model with its ten dimensions can guide leaders from schools and industry to create workplaces where feelings of meaningfulness, commitment, wisdom and peace are nurtured. This model focuses on meaningfulness, self-realization and inner motivation of the person, and links it with the mission and vision of the organization under a wise leadership understanding.

This study is based on a teacher sample within a qualitative design. For future studies, the researchers in the field of organizational management can research an empirical version of the proposed model and include employees from different sectors. Also, this study can be replicated in different geographies or countries as meaning can be affected by different cultures and beliefs, which may provide different cross-cultural results.

Acknowledgements. I am very much indebted to Pat Seaver, an Irish educator and teacher trainer, for his assistance as language editor. In editing the language of the article on online meetings, he has given a great insight to make this article more understandable from various cultural points and settings. I am also very thankful to the participants of the study for their generous responsiveness to my calls, mails and personal meetings any time required.

Ethics Committee Approval Information. Ethics committee approval was obtained from Harran University, Social and Human Sciences Ethics Committee for the research, with the date of April 09, 2020 and protocol number 76244175-752.01.01.

\section{References}

Ashmos, D. P., \& Duchon, D. (2000). Spirituality at work: A conceptualization and measure. Journal of Management Inquiry, 9(2), 134-145. https://doi.org/10.1177\%2F105649260092008

Barbuto Jr, J. E., \& Wheeler, D. W. (2006). Scale development and construct clarification of servant leadership. Group \& Organization Management, 31(3), 300-326. https://doi.org/10.1177/1059601106287091 
Bartels, B. E. \& Jackson, C. E. (2021). Meaning-centered leadership: Skills and strategies for increased employee well-being and organizational success. Rowman \& Littlefield Publishers.

Batubara, J. (2018). The meaningfulness of life in multiethnic perspective as the foundation for personal guidance. JOMSIGN: Journal of Multicultural Studies in Guidance and Counseling, 2(1), 72-81. https://doi.org/10.17509/jomsign.v2i1.10831

Baumeister, R. F., Vohs, K. D., Aaker, J. L., \& Garbinsky, E. N. (2013). Some key differences between a happy life and a meaningful life. The Journal of Positive Psychology, 8(6), 505-516. https://doi.org/10.1080/17439760.2013.830764

Birks, M., \& Mills, J. (2015). Grounded theory: A practical guide. Sage. https://doi.org/10.13140/2.1.2982.0484

Buble, M., Juras, A., \& Matić, I. (2014). The relationship between managers' leadership styles and motivation. Management: Journal of Contemporary Management Issues, 19(1), 161-193. https://hrcak.srce.hr/124612

Cambridge Dictionary (n.d.), https://dictionary.cambridge.org

Carton, A. M. (2018). "I'm not mopping the floors, I'm putting a man on the moon": How NASA leaders enhanced the meaningfulness of work by changing the meaning of work. Administrative Science Quarterly, 63(2), 323-369. https:// doi.org/10.1177/0001839217713748

Chalofsky, N. (2003). An emerging construct for meaningful work, Human Resource Development International, 6(1), 69-83. https://doi.org/10.1080/1367886022000016785

Chalofsky, N., \& Krishna, V. (2009). Meaningfulness, commitment, and engagement: The intersection of a deeper level of intrinsic motivation. Advances in Developing Human Resources, 11(2), 189-203. https://doi.org/10.1177/1523422309333147

Charmaz, K. (1996). The search for meanings-Grounded Theory. In. Smith, J. A., Harré, R., \& Van Langenhove, L. (Eds.), Rethinking methods in psychology (pp. 27-49). Sage.

Charmaz, K. (2006). Constructing grounded theory. Sage.

Chun-Tie, Y., Birks, M., \& Francis, K. (2019). Grounded theory research: A design framework for novice researchers. SAGE Open Medicine. 7, 1-8. https:// doi.org/10.1177/2050312118822927

Dantley, M. E. (2003). Purpose-driven leadership: The spiritual imperative to guiding schools beyond highstakes testing and minimum proficiency. Education and Urban Society, 35(3), 273-291. https:// doi.org/10.1177/0013124503252672

DeMara, C. (2018). Meaningful Leadership: How to Build Indestructible Relationships with Your Team Members Through Intentionality and Faith. DeMara-Kirby \& Associates, LLC.

Fairholm, G. W. (1996). Spiritual leadership: Fulfilling whole-self needs at work. Leadership \& Organization Development Journal, 17(5), 11-17. https://doi.org/10.1108/01437739610127469

Frankl, V. E. (2006). Man's search for meaning. Boston Beacon Press.

Frémeaux, S., \& Pavageau, B. (2020). Meaningful leadership: how can leaders contribute to meaningful work?. Journal of Management Inquiry, 1-13. https:// doi.org/10.1177/1056492619897126

Gårdheim. C. (2016). Unleash Your Creative Spirit!: The Guide to Building Your Dream Life. Balboa Press.

Giles, T. M., De Lacey, S., \& Muir-Cochrane, E. (2016). Coding, constant comparisons, and core categories. Advances in Nursing Science, 39(1), E29-E44. https:// doi.org/10.1097/ANS.0000000000000109

Göçen, A. \& Terzi R. (2019). Eğitim örgütleri için anlamlı iş ölçeği [Meaningful work scale for educational organizations]. Gazi Uiniversitesi Egitim Fakultesi Dergisi, 39(3), 1487-1512.

Graham, K. (2011). Leading with purpose: a case for soul leadership, Development and Learning in Organizations, 25(4), 5-7. https:// doi.org/10.1108/14777281111147026

Greenleaf, R. K. (2008). Who is the servant-leader?. The International Journal of Servant-Leadership, 4(1), 29-37.

Guba, E. G., \& Lincoln, Y. S. (1982). Epistemological and methodological bases of naturalistic inquiry. Educational Communication and Technology Journal, 30(4), 233-252.

Herrera, S. A. (2017). Exemplary leadership: A mixed-methods case study discovering how female chief executive officers create meaning (Order No. 10271696). Available from ProQuest Dissertations \& Theses Global. (1891739615). https://search.proquest.com/dissertations-theses/exemplary-leadership-mixed-methodscase-study/docview/1891739615/se-2?accountid=11301

Hodge, S. K. (2017). Meaning makers: A mixed-methods case study of exemplary chief executive officers of engineering technology organizations and the behaviors they use to create personal and organizational meaning (Order No. 10271689). Available from ProQuest Dissertations \& Theses Global. (1891735353). https://search.proquest.com/dissertations-theses/meaning-makers-mixed-methods-case-studyexemplary/docview $/ 1891735353 /$ se-2?accountid $=11301$

Holbeche, L., \& Springett, N. (2004). In search of meaning in the workplace. Roffey Park Institute. 
Hunter, A., Murphy, K., Grealish, A., Casey, D. \& Keady, J. (2011). Navigating the grounded theory terrain. Part 1. Nurse Researcher, 18(4), 6-10. https://doi.org/10.7748/nr2011.07.18.4.6.c8636

Jackson, C. E. (2017). Meaning-centered leadership: How exemplary technology leaders create organizational meaning (Order No. 10278375). Available from ProQuest Dissertations \& Theses Global. (1897559824). https://search.proquest.com/dissertations-theses/meaning-centered-leadership-howexemplary $/$ docview $/ 1897559824 /$ se-2?accountid $=11301$

Kalshoven, K., Den Hartog, D. N., \& De Hoogh, A. H. (2011). Ethical leadership at work questionnaire (ELW): Development and validation of a multidimensional measure. The Leadership Quarterly, 22(1), 51-69. https://doi.org/10.1016/j.leaqua.2010.12.007

Kerns, C. D. (2013). Clarity of purpose and meaningfulness at work: Key leadership practices. International Leadership Journal, 5(1), 27-44.

Kinjerski, V. M., \& Skrypnek, B. J. (2004). Defining spirit at work: Finding common ground. Journal of Organizational Change Management, 17(1), 26-42. https://doi.org/10.1108/09534810410511288

Klenke, K. (2005). Introducing spirituality, International Journal of Organisational Analysis, 13(1), 4-7. https://doi.org/10.1108/eb028994

Korotkov, D. L. (1998). The sense of coherence: Making sense out of chaos. In P. T. P. Wong \& P. Fry (Eds.), The human quest for meaning: A handbook of psychological research and clinical applications (pp. 51-70). Lawrence Erlbaum.

Kriger, M., \& Seng, Y. (2005). Leadership with inner meaning: A contingency theory of leadership based on the worldviews of five religions. The Leadership Quarterly, 16(5), 771-806. https://doi.org/10.1016/j.leaqua.2005.07.007

Lee, J. J., Clarke, C. L., Carson, M. N., \& Yang, S. C. (2018). How do Korean nursing students build knowledge? A constructivist grounded theory study. BMJ Open, 8, 1-10. https:// doi.org/10.1136/bmjopen-2018-022050

Lips-Wiersma, M., \& Morris, L. (2009). Discriminating between 'meaningful work'and the 'management of meaning'. Journal of Business Ethics, 88(3), 491-511. https:/ / doi.org/10.1007/s10551-009-0118-9

Maslow, A. H. (1969a). The farther reaches of human nature. Journal of Transpersonal Psychology, 1(1), 1-9

Maslow, A. H. (1969b). Toward a humanistic biology. American Psychologist, 24, 724-735

Matsuo, M., Arai, K., \& Matsuo, T. (2019). Empowering leadership and meaningful work: the mediating role of learning goal orientation. International Journal of Training and Development, 23(4), 328-338. https://doi.org/10.1111/ijtd.12165

Mautz, S. (2015). Make it matter: How managers can motivate by creating meaning. New York: AMACOM.

Milliman, J., Czaplewski, A. J., \& Ferguson, J. (2003). Workplace spirituality and employee work attitudes: An exploratory empirical assessment. Journal of Organizational Change Management, 16(4), 426-447. https://doi.org/10.1108/09534810310484172

Morin, E. M. (2008). The meaning of work, mental health and organizational commitment. (Studies and research/ Report No. R-585). Montréal: IRSST.

Mostafa, A. M. S., \& Abed El-Motalib, E. A. (2020). Ethical leadership, work meaningfulness, and work engagement in the public sector. Review of Public Personnel Administration, 40(1), 112-131. https://doi.org/10.1177/0734371X18790628

Nonaka, I., \& Takeuchi, H. (2011). The big idea: The wise leader. Harvard Business Review, 89(5), 58-67.

Parry, K., \& Bryman, A. (2006). Leadership in organizations. In S. R. Clegg, C. Hardy, T. B. Lawrence \& W. R. Nord (Eds.), The SAGE handbook of organization studies (pp. 447-468). Sage.

Patton, M. Q. (2014). Qualitative Evaluation and Research Methods. Sage.

Patton, M.Q. (1999). Enhancing the quality and credibility of qualitative analysis. Health Sciences Research, 34, 1189-1208

Phipps, K. A. (2010). Servant leadership and constructive development theory: How servant leaders make meaning of service. Journal of Leadership Education, 9(2), 151-170.

Robertson, K. M., O'Reilly, J., \& Hannah, D. R. (2020). Finding meaning in relationships: The impact of network ties and structure on the meaningfulness of work. Academy of Management Review, 45(3), 596-619. https://doi.org/10.5465/amr.2015.0242

Salkind, N. (2010). Triangulation. Encyclopedia of Research Design. Sage.

Shenton, A. K. (2004). Strategies for ensuring trustworthiness in qualitative research projects. Education for Information, 22(2), 63-75.

Sosik, J. J. (2000). The role of personal meaning in charismatic leadership. Journal of Leadership Studies, 7(2), 60-74. 
Strauss, A., \& Corbin, J. (1998). Basics of qualitative research (2nd ed.). Sage.

Thornton, L. F. (2018). What is Meaningful Leadership?. https://leadingincontext.com/2018/07/18/what-ismeaningful-leadership-part-1/

Thory, K. (2016). Developing meaningfulness at work through emotional intelligence training. International Journal of Training and Development, 20(1), 58-77. https://doi.org/10.1111/ijtd.12069

Ulrich, D., \& Ulrich, W. (2010). Leaders who make meaning meaningful. https://iveybusinessjournal.com/publication/leaders-who-make-meaning-meaningful/

Van Knippenberg, D. (2020). Meaning-based leadership. Organizational Psychology Review, 10(1), 6-28. https:// doi.org/10.1177\%2F2041386619897618

Varney, J. (2009). Leadership as meaning-making. Human Resource Management International Digest, 17(5), 3-5. https://doi.org/10.1108/09670730910974251

Yang, F., Huang, X., \& Wu, L. (2019). Experiencing meaningfulness climate in teams: How spiritual leadership enhances team effectiveness when facing uncertain tasks. Human Resource Management, 58(2), 155-168. https://doi.org/10.1002/hrm.21943

Zou, W., Zeng, Y., Peng, Q., Xin, Y., Chen, J., \& Houghton, J. D. (2020). The influence of spiritual leadership on the subjective well-being of Chinese registered nurses. Journal of Nursing Management, 28(6), 1432-1442. https://doi.org/10.1111/jonm.13106 